\title{
How Human Amygdala and Bed Nucleus of the Stria Terminalis May Drive Distinct Defensive Responses
}

\author{
Floris Klumpers, ${ }^{1,2}$ Marijn C.W. Kroes, ${ }^{1,3}$ Johanna M.P. Baas, ${ }^{4}$ and Guillén Fernández ${ }^{1}$ \\ ${ }^{1}$ Donders Institute for Brain, Cognition and Behaviour, Radboud University Medical Centre, 6525 EN Nijmegen, The Netherlands, ${ }^{2}$ Experimental \\ Psychopathology and Treatment Section, Behavioural Science Institute, Radboud University, 6525 HR Nijmegen, The Netherlands, ${ }^{3}$ Department of \\ Psychology and Center for Neural Science, New York University, New York, New York 10003, and ${ }^{4}$ Department of Experimental Psychology, Helmholtz \\ Institute, Utrecht University, 3584 CS Utrecht, The Netherlands
}

The ability to adaptively regulate responses to the proximity of potential danger is critical to survival and imbalance in this system may contribute to psychopathology. The bed nucleus of the stria terminalis (BNST) is implicated in defensive responding during uncertain threat anticipation whereas the amygdala may drive responding upon more acute danger. This functional dissociation between the BNST and amygdala is however controversial, and human evidence scarce. Here we used data from two independent functional magnetic resonance imaging studies $[n=108$ males and $n=70$ (45 females)] to probe how coordination between the BNST and amygdala may regulate responses during shock anticipation and actual shock confrontation. In a subset of participants from Sample $2(n=48)$ we demonstrate that anticipation and confrontation evoke bradycardic and tachycardic responses, respectively. Further, we show that in each sample when going from shock anticipation to the moment of shock confrontation neural activity shifted from a region anatomically consistent with the BNST toward the amygdala. Comparisons of functional connectivity during threat processing showed overlapping yet also consistently divergent functional connectivity profiles for the BNST and amygdala. Finally, childhood maltreatment levels predicted amygdala, but not BNST, hyperactivity during shock anticipation. Our results support an evolutionary conserved, defensive distancedependent dynamic balance between BNST and amygdala activity. Shifts in this balance may enable shifts in defensive reactions via the demonstrated differential functional connectivity. Our results indicate that early life stress may tip the neural balance toward acute threat responding and via that route predispose for affective disorder.

Key words: amygdala; anxiety; bed nucleus of the stria terminalis; defense; fear; functional MRI

Significance Statement

Previously proposed differential contributions of the BNST and amygdala to fear and anxiety have been recently debated. Despite the significance of understanding their contributions to defensive reactions, there is a paucity of human studies that directly compared these regions on activity and connectivity during threat processing. We show strong evidence for a dissociable role of the BNST and amygdala in threat processing by demonstrating in two large participant samples that they show a distinct temporal signature of threat responding as well as a discriminable pattern of functional connections and differential sensitivity to early life threat.

\section{Introduction}

Evolution equipped organisms with an array of defense systems that through appropriately timed recruitment allow optimal re-

\footnotetext{
Received Nov. 24, 2016; revised Aug. 10, 2017; accepted Aug. 15, 2017.

Author contributions: F.K., M.C.W.K., J.M.P.B., and G.F. designed research; F.K. performed research; F.K. and M.C.W.K. analyzed data; F.K., M.C.W.K., J.M.P.B., and G.F. wrote the paper.

We thank Sophie Akkermans, Nicole Driessen, Daphne Everaerd, Yuen Fang, Anita Harteveld, Sabine Kooijman, and Veerle van Son for technical assistance and excellent contributions to data acquisition.

The authors declare no competing financial interests.

Correspondence should be addressed to Dr. Floris Klumpers, Donders Center for Cognitive Neuroimaging, P.O.

Box 9101, NL-6500 HB Nijmegen, The Netherlands. E-mail: F.Klumpers@donders.ru.nl.
}

sponses to a multitude of dangerous situations (Davis et al., 2010; Hermans et al., 2014). Threat proximity is a critical factor to determine which defensive mode is selected (Blanchard et al., 1990; Fanselow, 1994; McNaughton and Corr, 2004). These modes represent qualitatively different functional repertoires for dealing with a threat according to its proximity and are rooted in evolutionary conserved ecological patterns of dealing with predator threat (Mobbs et al., 2015). For example, confrontation with a distant threat may elicit an attentive state of threat anticipation 
associated with phasic heart rate (HR) slowing (Bradley, 2009; Hagenaars et al., 2014). However, acute danger, such as when facing direct physical contact with a predator, may require instantaneous action to directly flee or fight. This switch into action has been associated with increased HR (Bradley et al., 2005; Löw et al., 2008).

Research in rodents suggests that defensive responses associated with threat anticipation and acute confrontation arise out of distinct neural circuits (Fanselow, 1994; Davis, 2006; Davis et al., 2010). These studies have mostly focused on the phase immediately preceding the actual aversive outcome and find that defensive responses to such acute threats appear mediated by the midbrain upon its activation by the amygdala (Davis and Whalen, 2001; McNaughton and Corr, 2004; Mobbs et al., 2007, 2015). Defensive responses during more distant threat anticipation might additionally involve anterior forebrain structures, in particular the bed nucleus of the stria terminalis (BNST; Davis, 2006; Duvarci et al., 2009; Davis et al., 2010; Fox et al., 2015a). The BNST, considered part of the extended amygdala, has strong connections with the amygdala and a strikingly similar cytoarchitecture (McDonald, 2003; Price, 2003).

Disentangling the neurocircuitry of defensive responses related to threat anticipation and acute confrontation could provide critical insight into fear- and anxiety-related psychopathology (Grillon, 2008; Davis et al., 2010; Grupe and Nitschke, 2013). Human functional magnetic resonance imaging (fMRI) studies have reported BNST activation to threat anticipation (Straube et al., 2007; Mobbs et al., 2010; Somerville et al., 2010; Alvarez et al., 2011; Grupe et al., 2013; McMenamin et al., 2014), yet little is known about potential differential contributions of the BNST and amygdala to human defense-related responses (cf. Alvarez et al., 2011; Fox et al., 2015a). Whether these regions have differential roles is debated given evidence for a large overlap in function and connectivity (Gungor and Paré, 2016; Shackman and Fox, 2016) as well as strong evidence that both regions are implicated in responding to distal threats in rodents (Davis et al., 2010; Tovote et al., 2015). Further, whether BNST and amygdala functioning might differentially mediate risk for developing stressrelated psychopathology is still unclear (Grupe and Nitschke, 2013; Fox et al., 2015a).

In the current study, cues signaling potential future electrical shock administration were presented to trigger a defensive mode of threat anticipation, expected to be associated with HR slowing. Direct physical confrontation with the shock was expected to trigger an acute confrontation defensive mode associated with HR acceleration. fMRI data from two independent samples $(n=$ 108 and $n=70$ ) were used to test differential involvement of the BNST and amygdala during each mode. First we confirmed that distinct HR reactions were associated with shock anticipation and confrontation in a subgroup of participants from Sample 2 with available ECG data (acquired outside the MRI scanner; $n=$ 48). Next we determined across both samples how our two regions-of-interest (ROIs) were associated with (1) distinct temporal signatures of responding to threat (Region $\times$ Mode interaction), (2) different patterns of functional connectivity, and (3) differential impact by major risk factors for anxiety-related psychopathology. For the latter we specifically tested relations with levels of early life stress in the form of childhood maltreatment (Heim and Nemeroff, 2001; Teicher and Samson, 2013) and trait anxiety (Barlow, 2000; Indovina et al., 2011).

\section{Materials and Methods}

Studies were approved by local medical ethical committees from Radboud University Medical Centre and University Medical Centre Utrecht (UMCU).

\section{Subjects}

Participants were recruited through advertisements posted around the Radboud University Medical Centre (Sample 1: 108 males) and Utrecht University (70 subjects, 21 males). All subjects were aged 18-30 (respective mean age $=21.8$ and 21.9 years, $\mathrm{SD}=2.5$ and 2.3 years) and reported no regular use of psychoactive drugs or history of neurological and psychiatric disorder, allowing us to evaluate interindividual differences in neural mechanisms related to psychopathology in a relatively homogeneous sample without disease related confounds (e.g., medication intake). After complete description of the study to the subjects, written informed consent was obtained.

The samples partly overlap with those of a previous investigation concerning an independent question about genetic variability in preparatory threat reactions (Klumpers et al., 2015b). The subjects were not explicitly selected based on genotype and previous analyses showed genotype distributions in both samples in accordance with the Hardy-Weinberg equilibrium. We analyzed only the directly relevant data from these datasets to avoid inflated type 1 error inherent to multiple testing. We nevertheless briefly describe the available data here for transparency (Simmons et al., 2011). Data from Sample 1 were selected from a large-scale project on individual differences in stress effects on various cognitive and affective domains including their neural underpinnings (Everaerd et al., 2015; Henckens et al., 2016). Only male participants were included in this study because of the difficulty in controlling for the effects of menstrual cycle on the stress response (Kirschbaum et al., 1999). In the context of this study we additionally acquired various stress coping personality scores (behavioral approach/avoidance scale, Beck depression Inventory, stress coping, neuroticism) and measures of stress reactivity in response to stressful movies (e.g., HR, blood pressure, cortisol) as well as fMRI data in the context of resting state, emotional face matching, and a declarative memory paradigm (Berkers et al., 2016). These data were not analyzed because they are not directly relevant to the current question (BIS/BAS, stress coping, fMRI data), showed only limited variation in this healthy sample (depression), were strongly associated to our primary measure of trait anxiety (NEO-Neuroticism), and/or not available in Sample 2 and not critical to the empirical question at hand (stress reactivity measures).

In the context of the study that included Sample 2, we had acquired personality characteristics of behavioral approach/avoidance, harm avoidance, novelty seeking, neuroticism, attentional control, and worry (Penn state worry questionnaire). In addition, there were behavioral data acquired regarding attentional bias to threats and attentional control. Again, we focused a priori on those measures that overlapped with Sample 1 and were of immediate relevance to the question at hand.

\section{Experimental designs}

Experiment 1. Subjects of Sample 1 were informed that they would see a yellow or blue square on a computer screen and would receive electrical shocks. The level of the shocks, administered to the fingers, was set before the experiment to a subjective intensity that was maximally uncomfortable without being painful. Subjects were instructed to pay attention to the screen and informed that a relationship existed between the stimuli and shocks. Colored squares were presented for $4 \mathrm{~s}$ in pseudorandomized order. Each stimulus was presented 18 times with an intertrial interval of 11-13 s. One square color (threat cue) coterminated with the presentation of the shock on one-third of the trials, the other color square (safe cue) was never paired with shock. Only non-reinforced trials were used for analyses (Klumpers et al., 2015b).

Experiment 2. Subjects of Sample 2 were explicitly informed beforehand that upon presentation of one particular picture of a male face with neutral facial expression (threat cue) a shock might be administered at any time (Klumpers et al., 2010). A second male face with neutral facial expression (safe cue) would never be paired with shock. Subjects were instructed to rest between trials and accordingly the word "REST" (in 
Dutch) was presented during the intertrial interval. As in Experiment 1, each subject underwent a standardized procedure to set shock intensities individually before the experiment (Klumpers et al., 2010). The experiment consisted of 42 presentations of each cue in semirandom order. Cue durations were jittered between 6 and $12 \mathrm{~s}$ with an intertrial interval of 8-12 s. Shock was administered at unpredictable timing $(0.5-11.5 \mathrm{~s}$ post-onset) during one of every six threat cues. This aimed to maximally reduce collinearity between cue onset, offset, and shock (Klumpers et al., 2010).

\section{Heart rate assessment}

Previously we showed that the anticipation of threat in both experiments produced robust increases in defensive responses indexed by skin conductance and startle responses (Klumpers et al., 2015b). Here, we specifically analyzed beat-to-beat HR variability because only HR would dissociate between states of ambiguous anticipation and an immediate fight/flight given (1) the continuous assessment of HR and (2) the bidirectional control of HR via the sympathetic and parasympathetic nervous system responses associated with action and action preparation respectively (cf. Bradley et al., 2005; Löw et al., 2015). We thus used ECG data available from a subsample of the subjects from Sample $2(n=48)$ who performed the same task in a separate session in the psychophysiological laboratory (Klumpers et al., 2012).

HR was continuously assessed during the task via a 3-lead placement at $2048 \mathrm{~Hz}$ with a Biosemi Active Two system and FLAT active Ag/Ag-Cl electrodes (Biosemi). Data were processed offline in Vision Analyzer (Brain Products). After filtering out signals of non-interest (high-pass $3 \mathrm{~Hz}, 24 \mathrm{~dB}$ /oct; low-pass $27 \mathrm{~Hz}, 24 \mathrm{~dB} /$ oct), automatic R-peak detection was performed using Analyzer's EKG solution. All segments were visually checked and, if necessary, thresholds for peak scoring and peak locations were manually corrected to ascertain that HR assessment was not disrupted due to artifacts such as movement or electrical stimulation. Next, inter-beat intervals (IBIs; the time between 2 consecutive R-peaks) were calculated and converted into HR in beats per minute (BPM). HR was extracted for all trials from $1 \mathrm{~s}$ before to $4 \mathrm{~s}$ poststimulus onset. To avoid contamination with (additional) shocks or startle probes, segments with additional stimuli occurring from $5.5 \mathrm{~s}$ prestimulus to $5.5 \mathrm{~s}$ poststimulus were excluded. For statistical analysis HR time series from $0.5 \mathrm{~s}$ prestimulus baseline to $4 \mathrm{~s}$ poststimulus baseline were subsequently downsampled to 1 value per $0.5 \mathrm{~s}$ and averaged per subject and stimulus (safe, threat, shock).

Data in beats per minute were evaluated statistically using repeated measures analyses of variance on 10 sequential time points relative to onset of either cue or electrical stimulation $(-0.5,0,0.5,1,1.5,2,2.5$, $3,3.5$, and $4 \mathrm{~s}$ ). All statistics were performed on these values, baseline corrected for $t=-1 \mathrm{~s}$ before stimulus onset. Greenhouse-Geisser degrees of freedom corrections for sphericity violations were applied when appropriate.

\section{Childhood maltreatment and trait anxiety assessment}

Childhood maltreatment was assessed in Sample 1 using a Dutch translation of the Childhood Trauma Questionnaire short form (CTQ-sf), a well validated questionnaire to assess early life trauma (Bernstein et al., 2003; Thombs et al., 2009). This 25 -item scale asks for childhood maltreatment on five subscales: sexual abuse, physical abuse, emotional abuse, emotional neglect, and physical neglect. Cronbach's $\alpha$ indicated high consistency of responses in our sample $(\alpha=0.82)$, indicating that subjects completed the questionnaire reliably. Trait anxiety was indexed through the trait portion of the Spielberger State-Trait Anxiety Inventory (Defares et al., 1980).

\section{MR-acquisition protocols}

Experiment 1. MR data of Experiment 1 were acquired on a $1.5 \mathrm{~T}$ Avanto MR scanner (Siemens) at the Donders Institute in Nijmegen. A series of $302 \mathrm{~T}^{*}$-weighted functional images were acquired using gradient echoplanar imaging with the following parameters: 32 oblique transverse slices, voxel size $=3.5 \times 3.3 \times 3.3 \mathrm{~mm}$, repetition time $(\mathrm{TR})=2.34 \mathrm{~s}$, flip angle $\alpha=90^{\circ}$, echo time (TE) $=35 \mathrm{~ms}$. A 3D magnetization-prepared rapid gradient echo anatomical $\mathrm{T} 1$-weigthed image was acquired for nor- malization purposes (176 slices, $1 \mathrm{~mm}$ isotropic, $\mathrm{TR}=2730 \mathrm{~ms}, \mathrm{TE}=$ $2.95 \mathrm{~ms})$.

Experiment 2. Imaging of Experiment 2 was performed on a Philips 3T Achieva MRI scanner (Philips Medical Systems) at UMCU. In three runs $2250 \mathrm{~T}^{\star}$-weighted volumes were acquired using a 3D PRESTO sequence ( 39 sagittal slices, voxel size $=3.5 \mathrm{~mm}$ isotropic, TR $=0.813 \mathrm{~ms}, \alpha=$ $\left.8.85^{\circ}, \mathrm{TE}=23 \mathrm{~ms}\right)$. A T1-weighted anatomical image was again obtained for normalization (175 slices, $1 \mathrm{~mm}$ isotropic, TR $=8.4 \mathrm{~ms}, \alpha=17^{\circ}$, $\mathrm{TE}=3.8 \mathrm{~ms}$ ).

\section{fMRI data analysis}

Functional scans from both experiments were realigned and coregistered to the anatomical scan in SPM8 (Wellcome Trust Centre for Neuroimaging, London, UK). Structural images were in SPM segmented and normalized to the Montreal Neurological Institute (MNI) 152 T1template image using the gray matter for calculation of the nonlinear transformation matrix. This matrix was used to spatially normalize all functional images. The normalized images ( $3.5 \mathrm{~mm}$ isotropic) were then smoothed with an isotropic 3D Gaussian kernel with $8 \mathrm{~mm}$ full-width at half-maximum. Time series inspection indicated global signal increases in scans surrounding shock administration, too large and abrupt to be blood oxygen level-dependent (BOLD) and potentially caused by movement or magnetic field distortions. Therefore, in both experiments, we used SPM's proportional scaling for analysis of the shock responses. This scan-by-scan scaling of each voxel according to the global scan average avoided that the artifacts could lead to artificial activations attributed to the shock. Indeed, we observed this scaling removed spurious activation in white matter/CSF. Nevertheless, analysis without scaling returned a highly similar dissociation between our ROIs.

In SPM8 general linear models were composed to relate BOLD signal variation in each voxel to the task conditions. The predictors of neural activity were the threat cues, safe cues, and shocks and these were modeled with boxcars with appropriate durations. Following previous work (Klumpers et al., 2010, 2015b), in Experiment 2 both the onset and offset responses to each cue were additionally modeled using a delta function $(0$ duration; analyses on offset responses to be reported elsewhere). Realignment parameters were included in the model as regressors of no interest. High-pass filtering (cutoff $128 \mathrm{~s}$ ) and a first-order autoregressive model were used as standard.

Reactions to threat and safe cues were contrasted in each subject to index shock anticipation. For Experiment 1 this entailed contrasting responses modeled by the $4 \mathrm{~s}$ boxcars. For Experiment 2, event-related responses to the threat onsets were compared with those of the safe cue. Analyses of the 6-12 s boxcar regressors in Experiment 2 revealed similar threat-responsive regions as reported below for the onset regressors (cf. Klumpers et al., 2010). Consistent with earlier work (Klumpers et al., 2015b) they are omitted for brevity, as the onset regressors are arguably more comparable to the data from Experiment 1 given the longer cue durations in the Experiment 2.

The single-subject contrast maps for shock anticipation (threat vs safe cue) and immediate threat (shock vs intertrial interval) were subsequently subjected to random effects analyses in the form of a one-sample $t$ test. Although these contrasts were chosen as the most adequate operationalization, the results were confirmed by additional analysis on the contrasts threat cue versus intertrial interval and shock versus either threat or safe cue. Important, each of these analyses gave similar results, i.e., a similar dissociation between BNST and amygdala. Whole-brain results were familywise error (FWE)-corrected for multiple comparisons according to random field theory $(p<0.05)$ and subsequently small volume FWE $p<0.05$ correction was applied for our two ROIs (after initial threshold $p<0.001$ uncorrected unless otherwise specified; Woo et al., 2014). All fMRI results figures are created in MRIcron, with use of the MRIcron $\mathrm{CH} 2$ better anatomical template image. Although we did not make predictions concerning the role of individual amygdala subregions, we report the location of reported amygdala activations relative to known cytoarchitectonic subregions of the amygdala using the SPM anatomy toolbox (Eickhoff et al., 2007). This toolbox provides an index of the probability that a given amygdala subregion is activated based on the overlap of the activation with probability maps of the centromedial 
amygdala (CMA), superficial amygdala (SFA), and basolateral amygdala (BLA). For this index, named $P_{\text {excess }}$, values $>1$ indicate that the activation overlaps with areas that have a high probability of belonging to that cytoarchitectonic region and $P_{\text {excess }}<1$ indicates that activation primarily intersects with peripheral regions (Eickhoff et al., 2007). The small size of these regions relative to our voxel size and smoothing kernel makes that these results should be mainly used as an indication of which subregion was activated most strongly and not as evidence for dissociation between regions.

To directly compare activity levels in each region during both stages of defensive processing we extracted mean contrast estimates for the main ROIs using the MARSBAR toolbox (Brett et al., 2002). The amygdala was defined using the automated anatomical labeling atlas (Maldjian et al., 2003). The BNST was defined based on a recent study that used ultra-high resolution MRI and a dedicated MR-pulse sequence to segment the BSNT from surrounding tissue (Avery et al., 2014). We used this anatomically defined BNST mask (normalized to MNI space) as kindly shared by the authors (Avery et al., 2014).

We performed functional connectivity analysis to investigate connectivity profiles for each region of interest (bilateral BNST and amygdala) in each sample. To this end we extracted in SPM each region's average activity time course over the experiment as reflected in the first eigenvariate. Regressors representing these time courses for both regions were added to the first level model for each experiment so that their correlation with other regions across the experiment could be explored. To minimize influence of confounds such as movement, we added for each subject an individually defined mean CSF time course as nuisance regressor. To confirm interconnectivity between amygdala and BNST we contrasted for both BNST and amygdala their respective time course with the CSF time course to control for global motion effects that may not have been eliminated from the data by including the standard motion regressors. Mean connectivity estimates for the ROIs were then extracted from this map to test interconnectivity. Subsequently, we obtained a map of regions showing stronger connectivity to either amygdala or BNST by directly contrasting the correlation maps for BNST and amygdala. We further verified whether activity and connectivity in our ROIs were affected by motion in additional analyses using framewise displacement as an index of movement (Power et al., 2014).

\section{Results}

\section{Heart rate analysis}

Shock anticipation and confrontation were associated with distinct cardiac responses as witnessed by main effects of stimulus (threat cue, safe cue, shock; $F_{(1.3,60.1)}=32.9, p<0.001$ ), time $\left(-0.5\right.$ to $\left.4 \mathrm{~s} ; F_{(2.8,132.9)}=4.4, p=0.007\right)$, and most critically a stimulus-by-time interaction $\left(F_{(3.5,165.8)}=15.9, p<0.001\right)$. As predicted, we observed greater HR deceleration during the threat

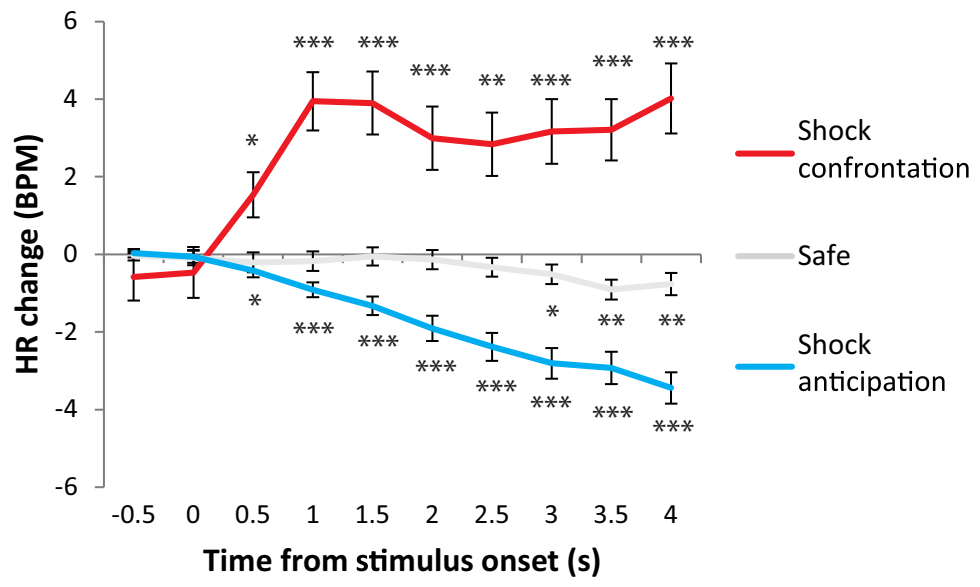

Figure 1. Shock anticipation and confrontation are associated with opposing cardiac reactions, indicative of distinct defensive modes. HR change to stimulus onset $(t=0)$ is plotted relative to a prestimulus baseline $(t=-1 \mathrm{~s})$. Threat cues (blue line) indicating possible forthcoming shock administration are associated with HR deceleration compared with safe cues (light gray). Conversely, the shock administration was followed by rapid HR acceleration (red). Error bars represent SEM. Asterisks indicate significant differences relative to the prestimulus baseline as indexed by paired $t$ tests, statistics relative to the safe cue are reported in the main text. ${ }^{* * *} p<0.001 ;{ }^{* *} p<0.01 ;{ }^{*} p<0.05$.

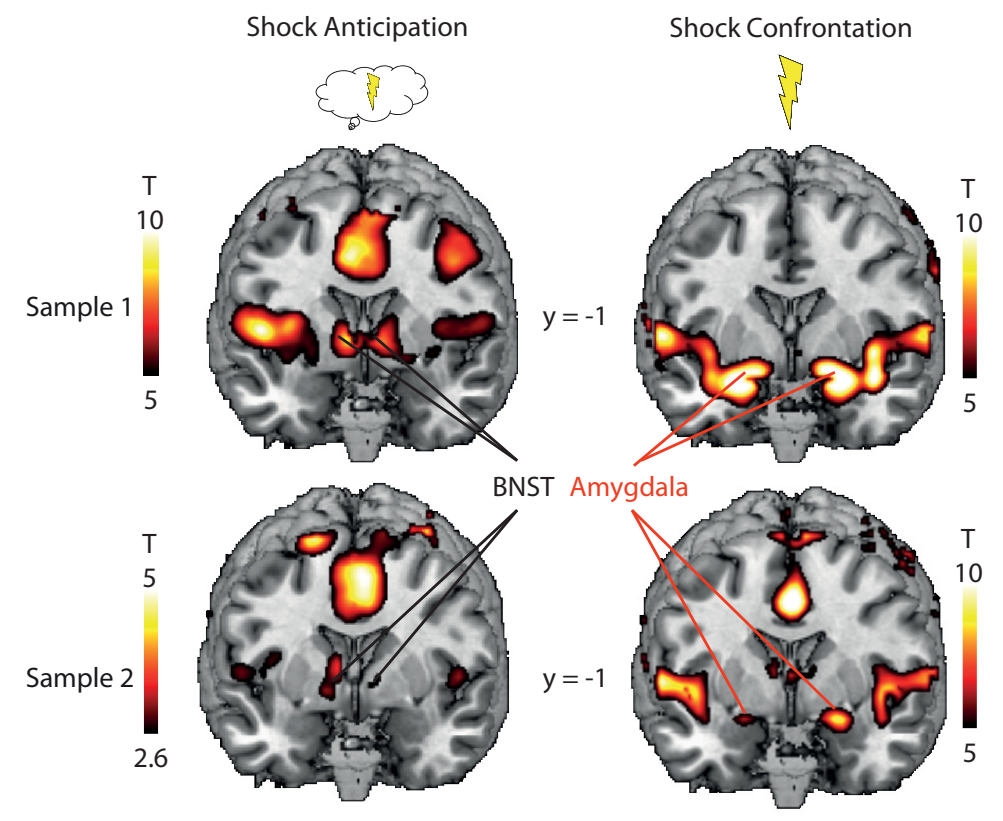

Figure 2. Voxelwise whole-brain fMRI results for Study 1 ( $N=108$; top row) and Study 2 ( $N=70$; bottom row) projected on a coronal slice $(y=-1)$ of an anatomical template image. Across studies, shock anticipation (threat cue vs safe cue) is consistently associated with BOLD fMRI responses in the basal forebrain region encompassing the bilateral BNST (left column) whereas shock confrontation (shock vs baseline) produced robust bilateral amygdala BOLD responses (right column). Images shown at wholebrain $p<0.05 \mathrm{FEW}$-corrected except for Study 2, anticipation phase, where the threshold is $p<0.005$ uncorrected to show the significant activation of the BNST (FWE small volume-corrected $p<0.05$ ).

cue compared with the safe cue (cue-by-time: $F_{(1.9,90.7)}=13.3$, $p<0.001)$. Follow-up tests indicated that the threat cue was associated with robust HR deceleration from $0.5 \mathrm{~s}$ onward (time effect: $F_{(1.9,88.9)}=33.1, p<0.001$; Fig. 1$)$. The safe cue was associated with a subtle HR deceleration (time effect: $F_{(2.6,124.1)}=3.3$, $p=0.03$ ). Conversely, HR acceleration was observed following the shock administration both relative to the safe cue (cue-bytime: $\left.F_{(2.9,135.5)}=10.6, p<0.001\right)$ and to the prestimulus baseline (time effect: $F_{(2.8,132.3)}=9.7, p<0.001$; Fig. 1). These results suggest that shock anticipation and confrontation are associated with opposite cardiac reactions linked respectively to passive vig- 


\begin{tabular}{|c|c|c|c|c|c|}
\hline \multirow[b]{2}{*}{ Shock anticipation (threat > safe) } & \multicolumn{3}{|c|}{$\begin{array}{l}\text { Peak coordinates, } \\
\text { MNI }\end{array}$} & \multirow{2}{*}{$\begin{array}{l}\text { Cluster } \\
\text { size, voxels }\end{array}$} & \multirow{2}{*}{$\begin{array}{l}\text { Foci } \\
Z \text { values }\end{array}$} \\
\hline & $x$ & $y$ & $z$ & & \\
\hline \multicolumn{6}{|l|}{ Sample $1(N=108)$} \\
\hline $\begin{array}{l}\mathrm{L}+\text { R insula/inferior frontal gyrus/rolandic } \\
\text { operculum/Thalamus/BNST/midbrain/ } \\
\text { brainstem }\end{array}$ & -28 & 26 & 4 & 8729 & $>8$ \\
\hline $\begin{array}{l}L+R \text { middle cingulate cortex/(pre)SMA } \\
\quad(\text { dmPFC) }\end{array}$ & -4 & -4 & 48 & 3635 & $>8$ \\
\hline L precentral gyrus/postcentral gyrus & -36 & -10 & 58 & 1746 & $>8$ \\
\hline R inferior parietal lobule & 64 & -38 & 26 & 1759 & $>8$ \\
\hline R precentral gyrus & 42 & 2 & 40 & 738 & 7.1 \\
\hline RSMA & 2 & -8 & 68 & 2 & 6.3 \\
\hline LSMA & -8 & -6 & 66 & 1 & 6.1 \\
\hline R middle cingulum & 12 & -24 & 42 & 114 & 5.8 \\
\hline RSMA & 16 & 2 & 66 & 1 & 5.7 \\
\hline L medial frontal gyrus & -10 & 46 & 54 & 38 & 5.6 \\
\hline R middle frontal gyrus & 30 & 42 & 22 & 50 & 5.5 \\
\hline R inferior parietal lobule & 40 & -46 & 40 & 33 & 5.4 \\
\hline RSMA & 14 & 10 & 68 & 1 & 5.3 \\
\hline L middle temporal gyrus & -50 & -52 & 8 & 11 & 5.1 \\
\hline RSMA & 14 & 16 & 64 & 1 & 5.0 \\
\hline$R$ cuneus & 16 & -64 & 38 & 4 & 5.0 \\
\hline L postcentral gyrus & -20 & -28 & 64 & 1 & 4.7 \\
\hline L amygdala $^{a}$ & -20 & 0 & -12 & 35 & 4.3 \\
\hline R amygdala $^{a}$ & 22 & 0 & -12 & 3 & 3.4 \\
\hline \multicolumn{6}{|l|}{ Sample $2(N=70)$} \\
\hline $\begin{array}{l}\mathrm{L}+\mathrm{R} \text { middle cingulate cortex/anterior } \\
\quad \text { cingulate/preSMA (dmPFC) }\end{array}$ & -7 & 10 & 42 & 57 & 5.1 \\
\hline LSMA & -18 & -4 & 70 & 6 & 5.0 \\
\hline L insula/inferior frontal gyrus & -35 & 18 & 7 & 24 & 4.9 \\
\hline RSMA & 18 & -7 & 74 & 14 & 4.8 \\
\hline L inferior parietal lobule & -60 & -28 & 24 & 3 & 4.6 \\
\hline R rectal gyrus & 4 & 32 & -18 & 1 & 4.6 \\
\hline L inferior frontal gyrus & 21 & 24 & -14 & 1 & 4.6 \\
\hline R postcentral gyrus & 28 & -42 & 70 & 1 & 4.5 \\
\hline R insula/inferior frontal gyrus & 42 & 24 & 4 & 1 & 4.5 \\
\hline $\mathbf{R B N S T}^{a}$ & 7 & 4 & 0 & 1 & 2.7 \\
\hline L BNST $^{a}$ & -7 & 0 & 4 & 2 & 2.7 \\
\hline
\end{tabular}

For highly robust results SPM gives no discrete $Z$-score, in these cases $Z$ values read $>8$. The main regions of interest are highlighted in bold font.

$L$, Left; $R$, right; dmPFC, dorsomedial prefrontal cortex.

${ }^{a}$ FWE small volume-corrected for the bilateral anatomical mask after an initial voxelwise threshold of $p<0.005$.

ilance and immediate reaction (Löw et al., 2008; Bradley, 2009; Hagenaars et al., 2014).

\section{Whole-brain fMRI analysis}

Initial whole-brain analyses in Sample 1 confirmed that shock anticipation was associated with BOLD signal increase in a bilateral basal forebrain region closely matching the anatomical location of the BNST which was replicated in the smaller Sample 2 at a lower threshold after small volume correction (Fig. 2; Table 1). These significant BOLD increases fell within our independent anatomical BNST definition (Study 1: 8/4/4 and -6/0/2 Study 2: $-7 / 0 / 4$ and 7/4/0; Table 1) and the Harvard-Oxford atlas suggests it is generally unlikely these peaks lie within subcortical regions directly surrounding the BNST (for caudate and thalamus the highest observed probabilities across both hemispheres and studies were $38 \%$ and $44 \%$; average probabilities across hemispheres and studies: caudate $17 \%$, thalamus $21 \%$, accumbens $0 \%$ ). Whole-brain corrected BOLD signal increases were also found in the dorsomedial prefrontal cortex and anterior insula. We found no evidence for amygdala activation during threat anticipation at whole-brain corrected significance levels (cf. Mechias et al., 2010; Fullana et al., 2016). At lower small-volume corrected thresholds, only in Sample 1 a large cluster of activation from the insula and striatum "spilled over" to the amygdala, particularly the centromedial aspects (Left: $P_{\text {excess }}$ CMA $=1.41$, $\mathrm{SFA}=1.05, \mathrm{BLA}=0.77$; right: $\mathrm{CMA}=1.22$, $\mathrm{SFA}=1.12, \mathrm{BLA}=$ 0.85 ; data not shown). Conversely, actual shock confrontation was associated with robust whole-brain corrected bilateral amygdala BOLD increases in both samples (Fig. 2). This activation centered in the superficial amygdala region (Study 1 left: $P_{\text {excess }} \mathrm{SFA}=1.46, \mathrm{BLA}=1.32, \mathrm{CMA}=1.07$; right $\mathrm{SFA}=1.54$, $\mathrm{BLA}=1.0, \mathrm{CMA}=0.79$; Study 2 left: $\mathrm{SFA}=1.53, \mathrm{CMA}=0.82$, $\mathrm{BLA}=0.58$; right $\mathrm{SFA}=1.30, \mathrm{CMA}=0.87, \mathrm{BLA}=0.53)$. The anterior insula and dorsal medial prefrontal cortex also exhibited BOLD increases following shock confrontation, but significant BOLD increases only extended into the right BNST for the larger sample (Table 2; Fig. 2). Only at lower thresholds the BNST showed a small volume corrected significant BOLD increase to shock confrontation in both samples (Table 2).

\section{Region $\times$ mode analysis}

To directly compare activity levels in each region during both modes of defensive processing we extracted mean activity level (indexed by the contrast value) from each anatomically defined region (Fig. $3 A$ ). $2 \times 2$ region-by-mode repeated-measures analysis revealed no main effect of region in either sample, indicating no differences between regions in overall signal. More important, both experiments showed a defensive mode-dependent switch in the relative activation of the anatomically defined BNST versus amygdala (region-by-mode interaction Sample 1: $F_{(1,107)}=86.9$; $p<0.001$, Sample 2: $\left.F_{(1,69)}=9.0 p=0.004\right)$. Follow-up analyses consistently indicated more prominent BNST BOLD signal increase during shock anticipation and a more prominent response in the amygdala during shock confrontation (Fig. 3B-E). During shock anticipation, BOLD increase was greater in the BNST than amygdala for each sample considered separately (Sample 1: $t_{(107)}=$ $7.8, p<0.001$; Fig. $3 B$; Sample $2: t_{(69)}=2.5, p=0.01$; Fig. $3 C$ ) and this was also true comparing to the amygdala subregions that showed most evidence for activation during this stage (BNST vs CMA and SFA; Study 1, $p$ values $<0.001$; Study 2, $p$ values $<0.01)$. Conversely, the amygdala evinced greater BOLD increases than the BNST during the period of shock confrontation $\left(t_{(107)}=7.8, p<0.001\right.$; Fig. $3 D ; t_{(69)}=2.0, p=0.05$; Fig. $\left.3 E\right)$. BNST BOLD increased during shock anticipation in both samples $\left(t_{(107)}=8.0, p<0.001\right.$ and $t_{(69)}=3.1, p=0.003$; Fig. $\left.3 B, C\right)$ but amygdala BOLD did not $\left(t_{(107)}=1.65, p=0.10\right.$ and $t_{(69)}<1$, n.s.; Fig. $3 B, C)$. In contrast, during shock confrontation the amygdala exhibited BOLD increases in each sample $\left(t_{(107)}=15.0\right.$, $p<0.001$ and $t_{(69)}=3.3, p=0.002$; Fig. $\left.3 D, E\right)$, whereas BNST BOLD increases to shock confrontation were only found in Sample $1\left(t_{(107)}=3.5, p=0.001\right.$ and $t_{(69)}<1$, n.s.; Fig. $\left.3 D, E\right)$. In sum, in each sample shock anticipation appeared associated with greater BNST activation, whereas shock confrontation was linked to more amygdala activity.

\section{Motion control analyses}

To check whether potential residual movement might explain the observed dissociation in regional activity, we correlated signal change in amygdala and BNST during our conditions of interest with mean framewise displacement (suggested by Power et al., 2014). Framewise displacement did not correlate with activity in our ROIs, except for a weak but significant correlation with the amygdala during shock anticipation in Sample $1(r=0.21, p=$ 
Table 2. Whole-brain results for BOLD responses associated with shock confrontation

\begin{tabular}{|c|c|c|c|c|c|}
\hline \multirow[b]{2}{*}{ Shock confrontation (shock > ITI) } & \multicolumn{3}{|c|}{ Peak coordinates, MNI } & \multirow{2}{*}{$\begin{array}{l}\text { Cluster } \\
\text { size, voxels }\end{array}$} & \multirow{2}{*}{$\begin{array}{l}\text { Foci } \\
\text { Zvalues }\end{array}$} \\
\hline & $x$ & $y$ & $z$ & & \\
\hline \multicolumn{6}{|l|}{ Sample $1(N=108)$} \\
\hline $\begin{array}{l}\text { R + L amygdala/inferior frontal gyrus/temporal pole/lingual gyrus/superior temporal gyrus/ } \\
\text { vermis/rolandic operculum/hippocampus/insula/thalamus/inferior temporal gyrus/ } \\
\text { supramarginal gyrus/posterior cingulate/cerebellum/R BNST }\end{array}$ & 22 & -2 & -16 & 16996 & $>8$ \\
\hline$L+R$ precuneus $/ L+R$ cuneus $/ L+R$ calcarine & 0 & -78 & 50 & 1091 & $>8$ \\
\hline L middle temporal gyrus & -56 & -60 & 10 & 561 & 7.4 \\
\hline $\mathrm{R}+\mathrm{L}$ anterior cingulate & 2 & 26 & 30 & 1299 & 7.3 \\
\hline $\mathrm{R}$ middle temporal gyrus & 60 & -56 & 4 & 376 & 7.0 \\
\hline $\mathrm{R}+\mathrm{L}$ middle cingulate & 2 & -14 & 36 & 107 & 6.8 \\
\hline L postcentral gyrus/precentral gyrus & -48 & -34 & 58 & 85 & 6.3 \\
\hline Rinferior frontal gyrus & 48 & 44 & 0 & 89 & 5.7 \\
\hline Left pons & -12 & -30 & -26 & 18 & 5.7 \\
\hline Left cerebellum & -18 & -42 & -46 & 17 & 5.6 \\
\hline Left cerebellum & -34 & -54 & -50 & 19 & 5.4 \\
\hline Left cerebellum & -4 & -28 & 6 & 1 & 4.8 \\
\hline Right thalamus & 6 & -28 & 6 & 1 & 4.8 \\
\hline Left insula & -36 & 2 & 12 & 1 & 4.8 \\
\hline \multicolumn{6}{|l|}{ Sample $2(N=70)$} \\
\hline L superior temporal gyrus/temporal pole/insula/middle temporal gyrus/rolandic operculum & -60 & -21 & 18 & 655 & $>8$ \\
\hline $\mathrm{R}+\mathrm{L}$ cingulate gyrus/postcentral gyrus/precentral gyrus & 0 & 4 & 42 & 762 & $>8$ \\
\hline $\begin{array}{l}\text { R rolandic operculum/postcentral gyrus/superior temporal gyrus/amygdala/ } \\
\text { insula/hippocampus/parahippocampal gyrus }\end{array}$ & 52 & -28 & 21 & 2314 & $>8$ \\
\hline L hippocampus/parahippocampal gyrus & -18 & -24 & -10 & 27 & $>8$ \\
\hline$L+R$ thalamus & 0 & -4 & 7 & 65 & $>8$ \\
\hline R middle + superior temporal gyrus & 60 & -60 & 7 & 76 & 6.7 \\
\hline R fusiform gyrus/inferior temporal gyrus & 56 & -63 & -21 & 75 & 6.5 \\
\hline Lamygdala & -21 & 0 & -14 & 8 & 6.2 \\
\hline$L+R$ cerebellum & 0 & -49 & -21 & 13 & 5.8 \\
\hline $\mathrm{L}$ cerebellum & -18 & -42 & -49 & 5 & 5.3 \\
\hline L precuneus & -4 & -42 & 52 & 8 & 5.2 \\
\hline R cerebellum & 21 & -46 & -49 & 3 & 4.8 \\
\hline L temporal pole & -42 & 24 & 21 & 1 & 4.6 \\
\hline $\mathrm{L}$ middle temporal gyrus & -56 & -70 & -7 & 1 & 4.6 \\
\hline $\mathbf{R B N S T}^{a}$ & 7 & 0 & 4 & 1 & 4.3 \\
\hline L BNST $^{a}$ & -7 & 0 & 4 & 1 & 3.1 \\
\hline
\end{tabular}

Highly similar results were obtained for shock versus threat and shock versus safe contrasts. All results are whole-brain voxelwise FWE-corrected $p<0.05$ unless otherwise specified and described in order of strongest activation ( $Z$ values). L, Left; R, right.

${ }^{a}$ FWE small volume-corrected for the bilateral anatomical mask after an initial voxelwise threshold of $p<0.001$.

0.03). A nonsignificant, but opposite correlation was observed for the amygdala activity during shock anticipation in Sample 2 (Sample 2: $r=-0.15, p=0.20$ ), making it unlikely that movement drove the consistently present condition effects. Including framewise displacement as a covariate in the region $\times$ defensive mode interaction analysis in Sample 1 indeed indicated the interaction of interest was still robustly present $\left(F_{(1,106)}=20.5, p<0.001\right)$. Together, there was no evidence for residual movement affecting our results of interest.

\section{Functional connectivity analysis}

In both samples we found mutual BNST-amygdala functional coupling during the tasks, extending previous reports on functional connectivity during rest (Avery et al., 2014; Torrisi et al., 2015). Thus, BOLD signal time course of the BNST was associated with that of the amygdala in both samples (Sample 1, left: $x=-22, y=-6, z=-12$; right: $x=24, y=-8, z=-14$; both $p_{\mathrm{FWE}}<0.001$; Sample 2, left: $x=-24, y=0, z=-21$; right: $x=$ $28, y=4, z=-18$; both $p_{\mathrm{FWE}}<0.001$ ), particularly with the superficial amygdala subregion (Study 1, left cluster: $P_{\text {excess }}$ $\mathrm{SFA}=1.21, \mathrm{CMA}=1.13, \mathrm{BLA}=1.04$; right: $\mathrm{SFA}=1.30, \mathrm{CMA}=$ $1.07, \mathrm{BLA}=1.07$; Study 2, left: $\mathrm{SFA}=1.57, \mathrm{BLA}=1.24, \mathrm{CMA}=$ 0.76 ; right: $\mathrm{SFA}=1.66, \mathrm{BLA}=1.24, \mathrm{CMA}=0.48)$. Likewise, the amygdala seed showed significant functional connectivity with the BNST in both samples (Sample 1, left: $x=-8, y=4, z=$ -4 ; right $x=8, y=4, z=-4$, both $p_{\mathrm{FWE}}<0.001$; Sample 2, left: $x=-7, y=4, z=-4$; right: $x=7, y=0, z=-4$; both $\left.p_{\mathrm{FWE}}<0.001\right)$.

Next we contrasted functional connectivity profiles for the BNST and amygdala to reveal each region's distinct functional connectivity with the rest of the brain. The BNST, compared with the amygdala, showed greater coupling with the striatum, hypothalamus, and perigenual medial prefrontal cortices in both samples (in each sample $p_{\mathrm{FWE}}<0.05$; Fig. 4 ; Table 3 ). The amygdala, relative to the BNST, showed more pronounced connectivity to the ventral occipital cortex, hippocampus, and to the brainstem in each sample ( $p_{\mathrm{FWE}}<0.05$ in both samples; Fig. 4 ; Table 3 ). Effects in other regions were not consistent between both samples (Fig. 4), possibly due to variation in sample size and duration/ timing differences between experiments. Regardless, the consistent findings indicate that the human BNST and amygdala show robust interconnectivity, yet distinct functional coupling to other regions. The BNST connected more with a striatal/prefrontal network, whereas the amygdala showed greater coupling to a ventrocaudal network including occipital cortex and brainstem.

Because framewise displacement has been shown to impact functional connectivity estimates even after realignment (Powers et al., 2011; cf. Satterthwaite et al., 2012), we verified all results 


\section{Shock Anticipation}

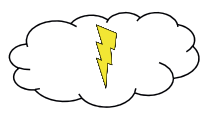

B

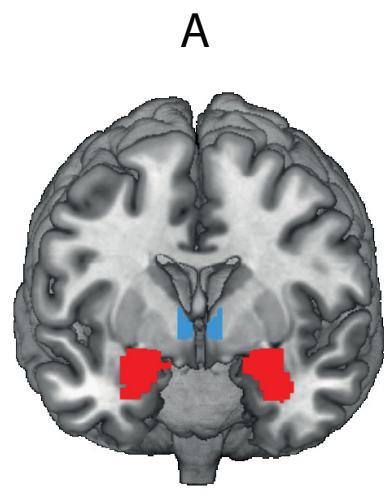

Sample 1

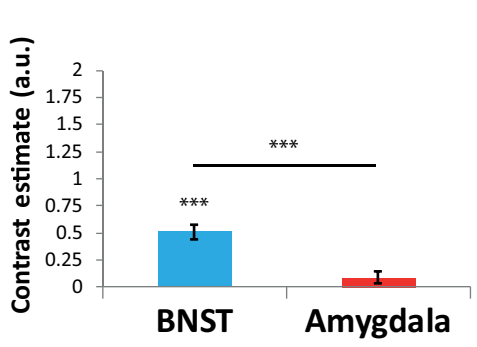

C

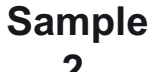

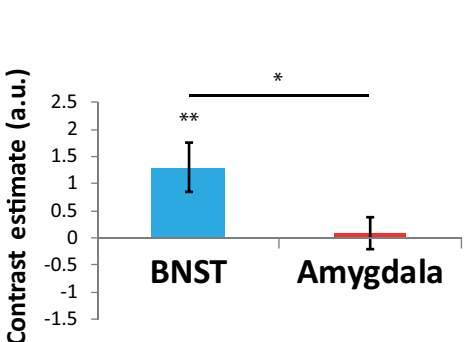

D

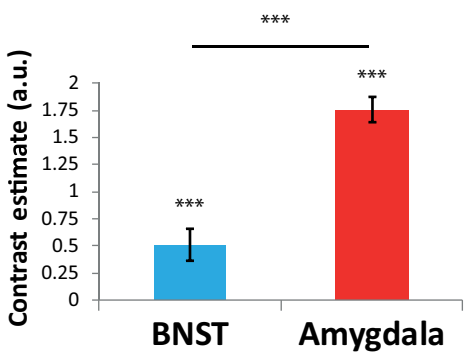

E

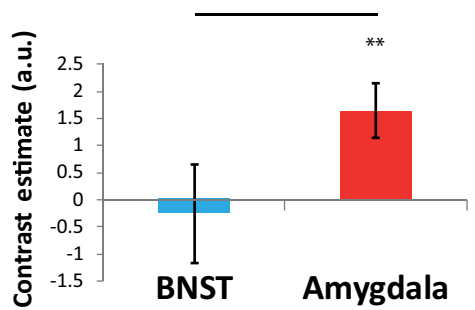

Figure 3. Extracted mean contrast values for the anatomically defined bilateral BNST (blue) and amygdala (red). $\boldsymbol{A}$, The anatomical mask used to define both structures plotted on an anatomical template image. Across studies, shock anticipation (threat vs safe cues; $\boldsymbol{B}, \boldsymbol{C}$ ) was associated with greater activity in the bilateral BNST, whereas shock confrontation was linked to higher bilateral amygdala activity $(\boldsymbol{D}, \boldsymbol{E})$. Error bars represent SEM. A.U., Arbitrary units. ${ }^{* * *} p<0.001 ;{ }^{* *} p<0.01 ;{ }^{*} p<0.05$.
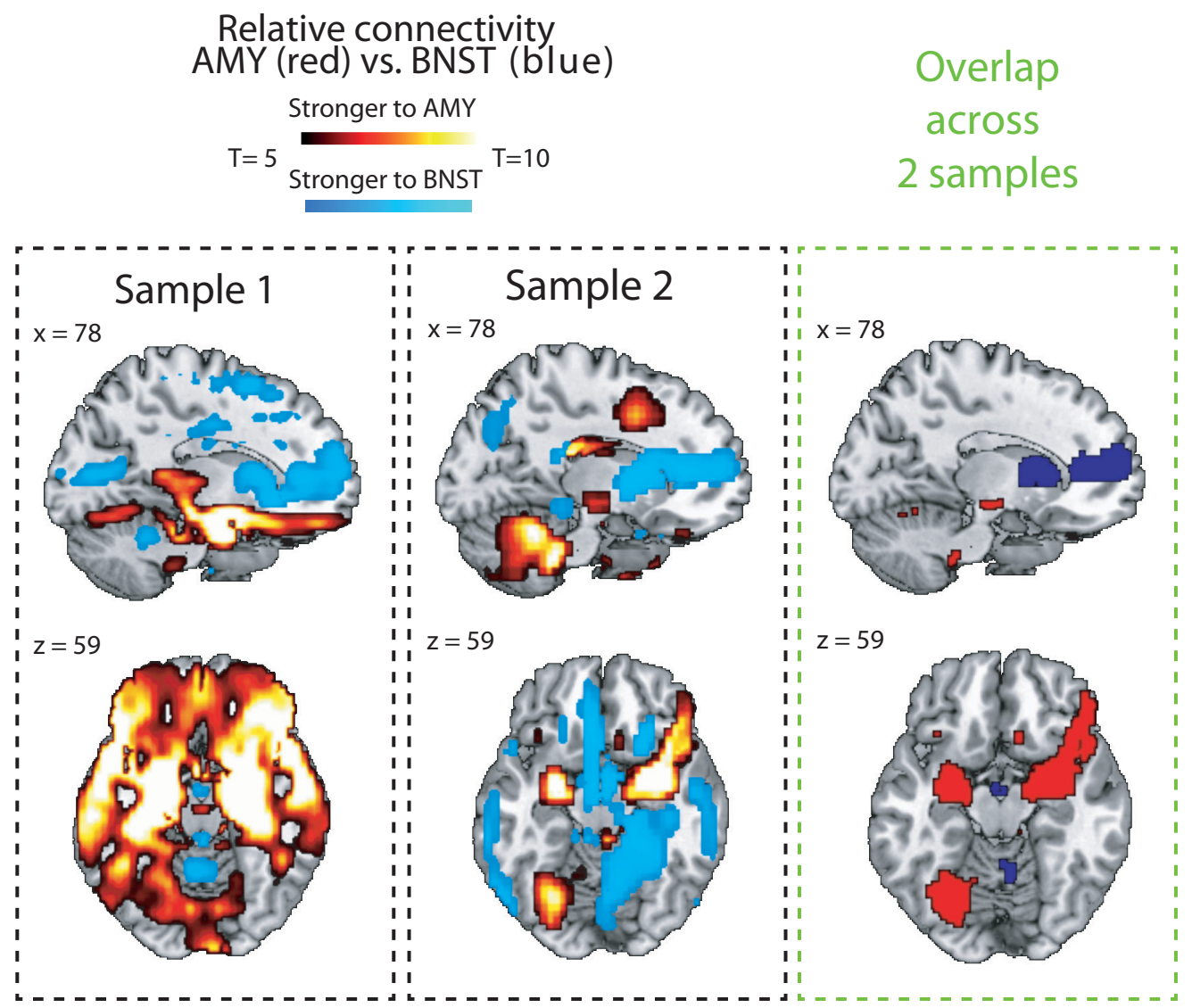

Figure 4. Regions with stronger connectivity to the BNST than amygdala (blue) and regions with more pronounced coupling to amygdala than BNST (red/yellow). Consistently stronger BNST coupling is found to the striatum, perigenual anterior cingulate cortex, and hypothalamus whereas the amygdala showed consistently stronger connectivity to visual cortex, hippocampus, and to the brainstem. All connectivity is displayed on consistent sagittal and axial slices of a template image $(x=-15, z=-14)$ whole-brain corrected for multiple comparisons at the voxel level $\left(p_{\mathrm{FWE}}<0.05\right)$. 
Table 3. Whole-brain results for functional connectivity differences between BNST and amygdala

\begin{tabular}{|c|c|c|c|c|}
\hline & \multicolumn{3}{|c|}{ Peak coordinates, MNI } & \multirow{2}{*}{$\begin{array}{l}\text { Cluste } \\
\text { size }\end{array}$} \\
\hline & $x$ & $y$ & $z$ & \\
\hline \multicolumn{5}{|l|}{ BNST > amygdala } \\
\hline $\begin{array}{l}\text { L + R BNST, caudate, perigenual cingulate cortex, } \\
\text { thalamus, midbrain, superior frontal gyrus }\end{array}$ & -7 & 3 & 0 & 4282 \\
\hline $\begin{array}{l}\text { R superior temporal gyrus/rolandic operculum/precentral } \\
\text { gyrus/posterior insula }\end{array}$ & 50 & -15 & 7 & 439 \\
\hline Lhypothalamus & -3 & -7 & -14 & 5 \\
\hline$L+R$ hypothalamus & 0 & -4 & -18 & 5 \\
\hline $\mathrm{L}$ corpus callosum/middle cingulate & -8 & -20 & 26 & 43 \\
\hline $\mathrm{R}$ cerebellum & 18 & -50 & -21 & 150 \\
\hline R white matter/insula & 29 & -35 & 18 & 38 \\
\hline R superior temporal gyrus, middle temporal gyrus & 56 & -38 & 14 & 482 \\
\hline $\mathrm{L}$ calcarine gyrus/lingual gyrus & -4 & 77 & 14 & 257 \\
\hline R inferior frontal gyrus & 29 & 25 & -4 & 27 \\
\hline $\mathrm{R}$ corticospinal tract//nferior frontal gyrus & 29 & 35 & -4 & 86 \\
\hline L cerebellum & -4 & -41 & -20 & 6 \\
\hline L white matter & -46 & -35 & -4 & 5 \\
\hline R inferior parietal gyrus & -47 & -46 & 51 & 11 \\
\hline \multicolumn{5}{|l|}{ Amygdala $>$ BNST } \\
\hline $\begin{array}{l}\text { R amygdala, hippocampus, parahippocampal gyrus, } \\
\text { midbrain, inferior frontal gyrus }\end{array}$ & 25 & -3 & -18 & 2476 \\
\hline $\begin{array}{l}\text { L amygdala, hippocampus, parahippocampal gyrus, } \\
\text { midbrain }\end{array}$ & -21 & -4 & -18 & 1104 \\
\hline R thalamus & 21 & -14 & 7 & 86 \\
\hline R brainstem & 11 & -32 & -21 & 38 \\
\hline $\mathrm{L}$ cerebellum/fusiform gyrus & -24 & -71 & -18 & 573 \\
\hline L Inferior frontal gyrus & -35 & 21 & -17 & 27 \\
\hline Lbrainstem & -14 & -38 & -42 & 65 \\
\hline R orbitofrontal gyrus, rectal gyrus & 11 & 18 & -18 & 139 \\
\hline Lhippocampus & -21 & -35 & 7 & 64 \\
\hline R orbitofrontal gyrus & 11 & 45 & -18 & 5 \\
\hline L inferior temporal gyrus & -53 & -32 & -24 & 16 \\
\hline R inferior temporal gyrus & 53 & -29 & -25 & 16 \\
\hline L thalamus & -18 & -17 & 4 & 21 \\
\hline$L+R$ brainstem & 1 & -35 & -25 & 11 \\
\hline L brainstem & -11 & -32 & -28 & 6 \\
\hline $\mathrm{L}+\mathrm{R}$ brainstem & 0 & -35 & -35 & 5 \\
\hline
\end{tabular}

Results are whole-brain voxelwise FWE-corrected $p<0.05$ in each sample and are described in order of strongest activation.

L, Left; R, right.

by adding mean framewise displacement as a covariate in the second level whole-brain analyses. Interconnectivity between the amygdala and BNST remained strongly significant in all tests $\left(p_{\text {FWE }}\right.$ all $\left.<0.005\right)$. Also, the differential connectivity results with FD as covariate were near identical to the results obtained without covariate, i.e., differential connectivity of the BNST and amygdala was again observed to all areas reported above. These additional analyses support the conclusion that the connectivity results are not driven by regionally differential motion sensitivity.

\section{Relation to risk factors for anxiety-related psychopathology}

Average childhood maltreatment scores in our healthy young volunteers were similar to previous community based samples (Scher et al., 2001), with considerable variance (CTQ mean: 32.9, $\mathrm{SD}=6.5$, range 25-56). Childhood maltreatment scores correlated positively with trait anxiety scores (Spearman rank correlation; $R_{\mathrm{s}}=0.39, p<0.001$ ), in line with the relevance of childhood maltreatment levels to adult well being.

To assess whether our predictors of stress-related psychopathology might influence the BNST and amygdala response to shock anticipation and confrontation we correlated childhood trauma and trait anxiety values to our four parameters-of- interest $(2$ regions $\times 2$ stages of extracted activation for our anatomical ROIs). After correction for multiple comparisons (Bonferroni adjusted critical $p=0.05 / 8$ tests $=0.004$ ), a positive correlation between childhood maltreatment scores and BOLD signal changes in the bilateral amygdala during shock anticipation remained $\left(R_{\mathrm{s}}=0.31, p=0.001\right.$; no other significant correlations: $p$ values $>0.083)$. This finding was confirmed in a voxelwise analysis which also returned a positive correlation between shock anticipation BOLD in the amygdala and childhood trauma scores (voxelwise peak: $x=-20, y=-2, z=-24$; $p_{\text {FWE }}=0.019$; Fig. $5 A-C$ ). Anatomical probabilities indicated the correlation cluster lies at the border of the superficial and basolateral amygdala $\left(P_{\text {excess }}\right.$ SFA $\left.=1.61, \mathrm{BLA}=1.09, \mathrm{CMA}=0.49\right)$. Interestingly the correlation between childhood trauma and anticipatory BNST BOLD response was near zero $\left(R_{\mathrm{s}}=0.07\right.$; Fig. $5 B)$ and, more importantly, a direct statistical comparison (Steiger, 1980; Meng et al., 1992) revealed the CTQ correlation was indeed stronger for the amygdala $(z=2.7 ; p=0.007)$. Follow-up analyses revealed that the amygdala correlation was primarily driven by the emotional neglect and abuse subscales $\left(R_{\mathrm{s}}=0.31, p=0.001\right.$ for both, other subscales $\left.R_{\mathrm{s}}<0.15\right)$, likely related to the fact that physical and sexual abuse were highly uncommon (average $<1$ point above minimum). Median split analysis further revealed that only subjects with higher childhood maltreatment scores showed significant amygdala BOLD increases during shock anticipation (high: $t_{(52)}=2.9, p=0.005$; low: $t_{(54)}<1$, n.s.; Fig. 5C,D).

\section{Discussion}

The current study provides a new demonstration that human defensive responses are a chain of dynamic neural reactions rather than a single uniform response (Blanchard et al., 1990; Fanselow, 1994; Löw et al., 2008; Mobbs et al., 2010; Grupe et al., 2013). Shock anticipation and confrontation with the actual outcome were found to be associated with opposite cardiac reactions and distinct neural responses. fMRI analysis indicated a switch from predominant BNST activity during shock anticipation to predominant amygdala activity during shock confrontation, reminiscent of findings in rodents with comparisons between phases of sustained and acute anticipation (Walker et al., 2003; Miles et al., 2011). The consistent distinct functional connectivity that we observed for these regions could be instrumental in instantiating appropriate behavior during these different defensive modes. Finally, we found that childhood maltreatment is linked to a shift in the activity balance between these regions during shock anticipation.

\section{A dissociable cardiac and neural response to shock anticipation and confrontation}

Across species, the sighting of a potential threat in the distance initially requires further evaluation. When confrontation with the danger subsequently draws near, this mode may need to be replaced by immediate action. The heightened environmental awareness required in the anticipation phase was previously linked to phasic cardiac deceleration whereas a switch toward action has been associated with phasic cardiac acceleration (Obrist et al., 1970; Bradley, 2009; Löw et al., 2015). In line with these findings, we observed that anticipation of potential future shock was linked to bradycardia and actual shock administration was associated with tachycardia. The heart is under complex parasympathetic and sympathetic control (Iwata and LeDoux, 1988). Our results indicate a relative shift toward sympathetic dominance when a threat becomes concrete. Although the current 
A

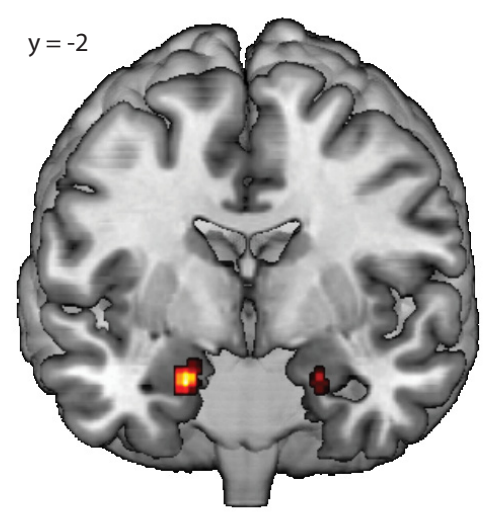

B

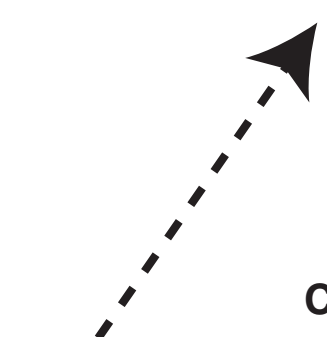

C

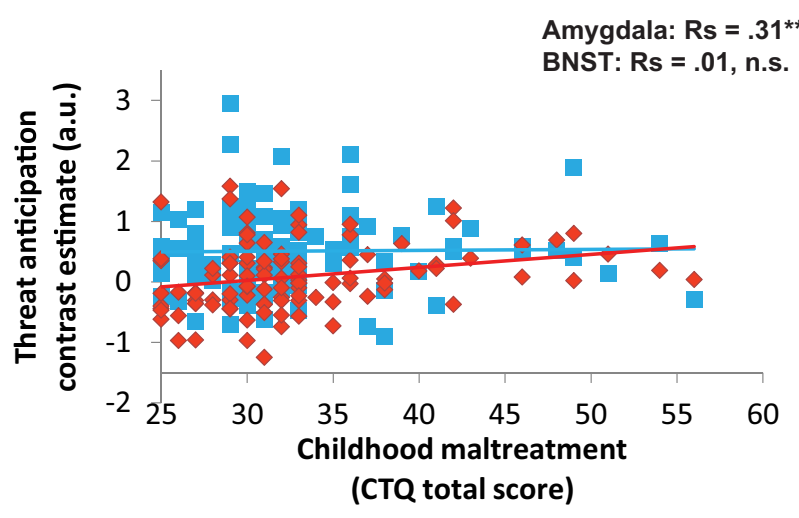

CTQ low

( $N=55)$

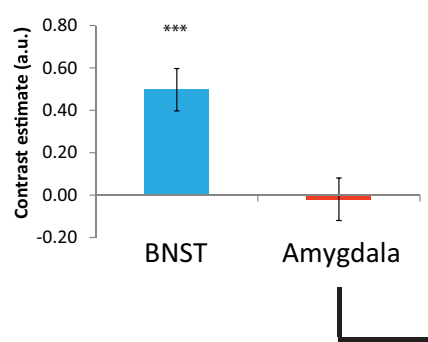

CTQ high

$(\mathrm{N}=53)$

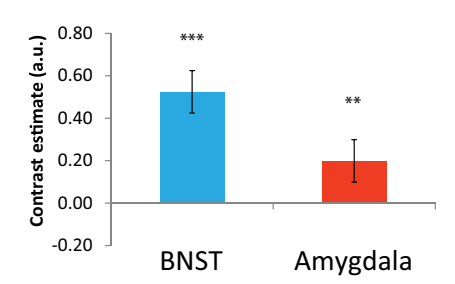

Figure 5. $\boldsymbol{A}$, Voxels in the bilateral amygdala with significantly stronger activity during the threat versus the safe cue for subjects with higher childhood maltreatment scores $(p<0.005$ uncorrected for illustrative purposes). B, Correlation for the bilateral amygdala (red) and BNST (blue) defined anatomically to avoid inflated correlation due to non-independence (Kriegeskorte et al., 2009; Vul et al., 2009). The correlation was significantly stronger in the amygdala (see Results section for statistics). Nonparametric Spearman rank correlations are reported here to protect against the impact of extreme values. Median split analysis $(\boldsymbol{C})$ demonstrated that only subjects with relatively high childhood maltreatment scores showed amygdala BOLD increases during shock anticipation. BNST BOLD increases occurred in both groups. Note: maltreatment scores were only available in Sample 1. Error bars represent SEM. ${ }^{* *} p<0.001 ;{ }^{* *} p<0.01 ;{ }^{*} p<0.05$.

study did not include any overt behavioral measures, previous literature suggests such a shift might support flight/fight behavior (Bradley, 2009) and may reduce impact of painful stimuli (Garfinkel and Critchley, 2016).

We probed the neural circuits associated with the two distinct defensive modes, focusing on the BNST and amygdala mainly due to their demonstrated importance in nonhuman studies. During shock anticipation we found activation of a ventral striatal region that matched the location of the BNST in two samples. The BNST is a small region that surrounds the internal capsula like a ring and can be challenging to definitively identify using conventional neuroimaging techniques (Fox et al., 2015a). Thus, the current study used an independent anatomical definition from ultra-high resolution MRI research (Avery et al., 2014). Although our study is limited due to the relatively low fMRI resolution (Gungor and Paré, 2016), the peak activation observed during shock anticipation was consistent with this previously identified anatomical location.

We found no evidence for amygdala activation during shock anticipation despite observing robust psychophysiological defense reactions at this stage (Klumpers et al., 2015b). We observed robust amygdala responses in the same experiments to shock however, demonstrating our fMRI acquisition method was sensitive to amygdala responses. The lack of amygdala activation during shock anticipation may appear counterintuitive given previous evidence from particularly rodent research that the amygdala plays a critical role in driving threat-related defensive reactions during anticipatory states (Davis and Whalen, 2001; Davis, 2006; Davis et al., 2010), yet a lack of amygdala activation is not uncommon among human shock anticipation studies (cf. Mechias et al., 2010; Fullana et al., 2016 for meta-analysis). One explanation for stronger amygdala involvement in nonhuman experiments during anticipation is that threat intensity is typically higher, and ambiguity lower, than in human studies (Dunsmoor et al., 2007), indeed in our current studies we used reinforcement rates of $33 \%$ and $16 \%$, which creates considerable ambiguity. Although our finding of robust amygdala activation during acute confrontation matched rodent evidence, it deserves mention that the rodent studies typically investigated acute threat reactions in the immediate period before a threat occurs. Here, we investigated the actual aversive outcome and found a similar pattern. A limitation to this finding is the lack of a tactile nonthreatening stimulus to serve as a control in our shock confrontation fMRI contrast. Such a control would provide a more specific test of the neural regions involved in responding to an aversive outcome. Nevertheless, our data are consistent with a broader human literature demonstrating amygdala responding to acute, unconditioned affective stimuli (Davis and Whalen, 2001; Zald, 2003), and with variation in amygdala responses during more ambiguous, conditioned states of shock anticipation (Indovina et al., 2011). Of note, our findings also align with the well known role for the amygdala in learning to predict threat 
(Bechara et al., 1995; Johansen et al., 2011; Klumpers et al., 2015a) with strongest activity at the actual moment when sensory information regarding acute danger and threat-predicting cues converge (Johansen et al., 2011; Li et al., 2011).

\section{Dissociating roles of the BNST and amygdala}

Both the BNST and amygdala have been described as critical for autonomic and neuroendocrine control in the context of threat. With similar anatomical connections, these regions may both serve as an intermediate between higher-order emotion processing regions (e.g., medial prefrontal cortex and hippocampus) and regions more directly involved in instantiating defensive responses (e.g., brainstem and hypothalamus; Davis and Whalen, 2001; Crestani et al., 2013). The current data support previous evidence for extensive crosstalk between the two regions (Oler et al., 2012, 2017; Avery et al., 2014; Torrisi et al., 2015). However, we demonstrate that these regions also differ in the relative strength of functional connectivity to a number of brain regions. Also after checks for potential residual movement effects, our results appeared robust and match well to previous findings from anatomical and functional studies into these regions.

The BNST exhibited greater functional connectivity with medial prefrontal cortex, caudate, thalamus, and hypothalamus. All these regions have been consistently shown to have strong functional and structural connections to the BNST (Avery et al., 2014; Krüger et al., 2015; Torrisi et al., 2015; Gorka et al., 2017). During anticipation, tight BNST connections to the striatum and prefrontal cortex might help predict potential outcomes and plan appropriate action. Connectivity between the BNST and hypothalamus could initiate long-lasting endocrine responses but also fast autonomic reactions such as bradycardia. Indeed, rodent studies report a modulatory role for the BNST in cardiovascular reactions, linking its activity to bradycardia (Crestani et al., 2013).

The amygdala was found to have greater functional coupling with the visual cortex, orbitofrontal cortex, hippocampus, and brainstem which all have demonstrated structural and functional connections to the amygdala (Price, 2003; van Marle et al., 2010; Kim et al., 2011). This amygdala network may mediate instantaneous responses to incoming stimuli during acute danger and strengthen memories associating threat cues with danger. Although we did not have the resolution to disentangle different brainstem regions, the regions found to connect stronger to the amygdala here encompass the periaqueductal gray and locus ceruleus. Both are known to drive HR changes (Lovick et al., 1995; Hermans et al., 2013; Wang et al., 2014). Moreover, human amygdala activity is linked to tachycardia (Critchley et al., 2005; Hermans et al., 2011; Jones et al., 2015) and amygdala inactivation in the rodent can block tachycardia (Nalivaiko et al., 2007; Oscar et al., 2015), suggesting a potential causal role for the amygdala in driving tachycardia during acute danger via brainstem regions.

Our final question concerned individual differences in the recruitment of the BNST and amygdala during both defensive modes. We found initial evidence that early life stress affects the dynamic activity balance between the BNST and amygdala. Specifically, individuals who experienced more childhood maltreatment showed amygdala hyper-activation during shock anticipation. We could not link this neural change to physiological reactions because childhood maltreatment scores and HR recordings were not available in the same subjects. However this finding does dovetail with research showing that in more fearful subjects, the characteristic HR deceleration during shock antici- pation is replaced by HR acceleration (Klorman et al., 1977; Hamm and Vaitl, 1996; Hamm et al., 1997). Interestingly, also amygdala-dependent threat learning is boosted after stress in a well known animal model of post-traumatic stress (Rau et al., 2005). Our findings also match previous findings of traumarelated amygdala hyper-activation during the processing of emotional faces (McCrory et al., 2011; van Harmelen et al., 2013) and extend these by showing amygdala hyper-activation during shock anticipation. This is important because excessive threat anticipation is a primary symptom across anxiety disorders (Barlow, 2000; Grupe and Nitschke, 2013). Together with this previous work, our data suggest that the brains of individuals at risk to develop psychopathology respond to distant threat almost as if confronted with acute danger, particularly when a genetic predisposition is present. Heritable hypermetabolism of both the BNST and amygdala has been demonstrated in rhesus monkeys high in anxious temperament following threat exposure (Fox et al., 2015b; Shackman et al., 2017). Our initial, correlational finding needs to be replicated and extended to clinical populations yet tentatively suggests that early life stress may in interaction with genetic predispositions cause a psychobiological vulnerability to show exaggerated defensive responses to distant threats causing a variety of fear- and anxiety-related symptoms (Barlow, 2000).

\section{Conclusion}

In conclusion, this study reveals a shift in activity balance from the human BNST to the amygdala when moving from a mode of threat anticipation to confrontation. Combined with previous work, our findings indicate that together the BNST and amygdala orchestrate a chain of neural processes leading to distinct defensive responses. The balance in the relative contribution of either structure may shift based on the proximity of a threat, enabling appropriate responses via connectivity with specific effectors. Childhood maltreatment might cause this shift to occur more readily, and this suggests a potential mechanism for how early life stress predisposes individuals to be hypersensitive to potential future threats.

\section{Notes}

Given previous findings in this dataset the authors tested the impact of 5-HTT genetics on the newly assessed parameters of interest. These results are available from the Donders Institute repository online at (http://hdl.handle.net/11633/di.dccn.DSC_ 3013009.13_445). This material has not been peer reviewed.

\section{References}

Alvarez RP, Chen G, Bodurka J, Kaplan R, Grillon C (2011) Phasic and sustained fear in humans elicits distinct patterns of brain activity. Neuroimage 55:389-400. CrossRef Medline

Avery SN, Clauss JA, Winder DG, Woodward N, Heckers S, Blackford JU (2014) BNST neurocircuitry in humans. Neuroimage 91:311-323. CrossRef Medline

Barlow DH (2000) Unraveling the mysteries of anxiety and its disorders from the perspective of emotion theory. Am Psychol 55:1247-1263. CrossRef Medline

Bechara A, Tranel D, Damasio H, Adolphs R, Rockland C, Damasio AR (1995) Double dissociation of conditioning and declarative knowledge relative to the amygdala and hippocampus in humans. Science 269:11151118. CrossRef Medline

Berkers RM, Klumpers F, Fernández G (2016) Medial prefrontal-hippocampal connectivity during emotional memory encoding predicts individual differences in the loss of associative memory specificity. Neurobiol Learn Mem 134:44-54. CrossRef Medline

Bernstein DP, Stein JA, Newcomb MD, Walker E, Pogge D, Ahluvalia T, Stokes J, Handelsman L, Medrano M, Desmond D, Zule W (2003) De- 
velopment and validation of a brief screening version of the childhood trauma questionnaire. Child Abuse Negl 27:169-190. CrossRef Medline

Blanchard RJ, Blanchard DC, Rodgers J, Weiss SM (1990) The characterization and modelling of antipredator defensive behavior. Neurosci Biobehav Rev 14:463-472. CrossRef Medline

Bradley MM (2009) Natural selective attention: orienting and emotion. Psychophysiology 46:1-11. CrossRef Medline

Bradley MM, Moulder B, Lang PJ (2005) When good things go bad: the reflex physiology of defense. Psychol Sci 16:468-473. CrossRef Medline

Brett M, Anton J, Valabregue R, Poline J (2002) Region of interest analysis using an SPM toolbox [abstract]. Presented at the 8th International Conference on Functional Mapping of the Human Brain. Sendai, Japan.

Crestani CC, Alves FH, Gomes FV, Resstel LB, Correa FM, Herman JP (2013) Mechanisms in the bed nucleus of the stria terminalis involved in control of autonomic and neuroendocrine functions: a review. Curr Neuropharmacol 11:141-159. CrossRef Medline

Critchley HD, Rotshtein P, Nagai Y, O’Doherty J, Mathias CJ, Dolan RJ (2005) Activity in the human brain predicting differential heart rate responses to emotional facial expressions. Neuroimage 24:751-762. CrossRef Medline

Davis M (2006) Neural systems involved in fear and anxiety measured with fear-potentiated startle. Am Psychol 61:741-756. CrossRef Medline

Davis M, Whalen PJ (2001) The amygdala: vigilance and emotion. Mol Psychiatry 6:13-34. CrossRef Medline

Davis M, Walker DL, Miles L, Grillon C (2010) Phasic vs sustained fear in rats and humans: role of the extended amygdala in fear vs anxiety. Neuropsychopharmacology 35:105-135. CrossRef Medline

Defares PB, Ploeg HMvd, Spielberger CD (1980) Een nederlandstalige bewerking van de Spielberger State-Trait Anxiety Inventory: de ZelfBeoordelings Vragenlijst. De Psycholoog 15:460-467.

Dunsmoor JE, Bandettini PA, Knight DC (2007) Impact of continuous versus intermittent CS-UCS pairing on human brain activation during Pavlovian fear conditioning. Behav Neurosci 121:635-642. CrossRef Medline

Duvarci S, Bauer EP, Paré D (2009) The bed nucleus of the stria terminalis mediates inter-individual variations in anxiety and fear. J Neurosci 29 : 10357-10361. CrossRef Medline

Eickhoff SB, Paus T, Caspers S, Grosbras MH, Evans AC, Zilles K, Amunts K (2007) Assignment of functional activations to probabilistic cytoarchitectonic areas revisited. Neuroimage 36:511-521. CrossRef Medline

Everaerd D, Klumpers F, van Wingen G, Tendolkar I, Fernández G (2015) Association between neuroticism and amygdala responsivity emerges under stressful conditions. Neuroimage 112:218-224. CrossRef Medline

Fanselow MS (1994) Neural organization of the defensive behavior system responsible for fear. Psychon Bull Rev 1:429-438. CrossRef Medline

Fox AS, Oler JA, Tromp do PM, Fudge JL, Kalin NH (2015a) Extending the amygdala in theories of threat processing. Trends Neurosci 38:319-329. CrossRef Medline

Fox AS, Oler JA, Shackman AJ, Shelton SE, Raveendran M, McKay DR, Converse AK, Alexander A, Davidson RJ, Blangero J, Rogers J, Kalin NH (2015b) Intergenerational neural mediators of early-life anxious temperament. Proc Natl Acad Sci U S A 112:9118-9122. CrossRef Medline

Fullana MA, Harrison BJ, Soriano-Mas C, Vervliet B, Cardoner N, ÀvilaParcet A, Radua J (2016) Neural signatures of human fear conditioning: an updated and extended meta-analysis of fMRI studies. Mol Psychiatry 21:500-508. CrossRef Medline

Garfinkel SN, Critchley HD (2016) Threat and the body: how the heart supports fear processing. Trends Cogn Sci 20:34-46. CrossRef Medline

Gorka AX, Torrisi S, Shackman AJ, Grillon C, Ernst M (2017) Intrinsic functional connectivity of the central nucleus of the amygdala and bed nucleus of the stria terminalis. Neuroimage. Advance online publication. doi: 10.1016/j.neuroimage.2017.03.007. Medline

Grillon C (2008) Models and mechanisms of anxiety: evidence from startle studies. Psychopharmacology 199:421-437. CrossRef Medline

Grupe DW, Nitschke JB (2013) Uncertainty and anticipation in anxiety: an integrated neurobiological and psychological perspective. Nat Rev Neurosci 14:488-501. CrossRef Medline

Grupe DW, Oathes DJ, Nitschke JB (2013) Dissecting the anticipation of aversion reveals dissociable neural networks. Cereb Cortex 23:18741883. CrossRef Medline

Gungor NZ, Paré D (2016) Functional heterogeneity in the bed nucleus of the stria terminalis. J Neurosci 36:8038-8049. CrossRef Medline

Hagenaars MA, Oitzl M, Roelofs K (2014) Updating freeze: aligning animal and human research. Neurosci Biobehav Rev 47:165-176. CrossRef Medline

Hamm AO, Vaitl D (1996) Affective learning: awareness and aversion. Psychophysiology 33:698-710. CrossRef Medline

Hamm AO, Cuthbert BN, Globisch J, Vaitl D (1997) Fear and the startle reflex: blink modulation and autonomic response patterns in animal and mutilation fearful subjects. Psychophysiology 34:97-107. CrossRef Medline

Heim C, Nemeroff CB (2001) The role of childhood trauma in the neurobiology of mood and anxiety disorders: preclinical and clinical studies. Biol Psychiatry 49:1023-1039. CrossRef Medline

Henckens MJ, Klumpers F, Everaerd D, Kooijman SC, van Wingen GA, Fernández G (2016) Interindividual differences in stress sensitivity: basal and stress-induced cortisol levels differentially predict neural vigilance processing under stress. Soc Cogn Affect Neurosci 11:663-673. CrossRef Medline

Hermans EJ, van Marle HJ, Ossewaarde L, Henckens MJ, Qin S, van Kesteren MT, Schoots VC, Cousijn H, Rijpkema M, Oostenveld R, Fernández G (2011) Stress-related noradrenergic activity prompts large-scale neural network reconfiguration. Science 334:1151-1153. CrossRef Medline

Hermans EJ, Henckens MJ, Roelofs K, Fernández G (2013) Fear bradycardia and activation of the human periaqueductal grey. Neuroimage 66:278287. CrossRef Medline

Hermans EJ, Henckens MJ, Joëls M, Fernández G (2014) Dynamic adaptation of large-scale brain networks in response to acute stressors. Trends Neurosci 37:304-314. CrossRef Medline

Indovina I, Robbins TW, Núñez-Elizalde AO, Dunn BD, Bishop SJ (2011) Fear-conditioning mechanisms associated with trait vulnerability to anxiety in humans. Neuron 69:563-571. CrossRef Medline

Iwata J, LeDoux JE (1988) Dissociation of associative and nonassociative concomitants of classical fear conditioning in the freely behaving rat. Behav Neurosci 102:66-76. CrossRef Medline

Johansen JP, Cain CK, Ostroff LE, LeDoux JE (2011) Molecular mechanisms of fear learning and memory. Cell 147:509-524. CrossRef Medline

Jones CL, Minati L, Nagai Y, Medford N, Harrison NA, Gray M, Ward J, Critchley HD (2015) Neuroanatomical substrates for the volitional regulation of heart rate. Front Psychol 6:300. CrossRef Medline

Kim MJ, Loucks RA, Palmer AL, Brown AC, Solomon KM, Marchante AN, Whalen PJ (2011) The structural and functional connectivity of the amygdala: from normal emotion to pathological anxiety. Behav Brain Res 223:403-410. CrossRef Medline

Kirschbaum C, Kudielka BM, Gaab J, Schommer NC, Hellhammer DH (1999) Impact of gender, menstrual cycle phase, and oral contraceptives on the activity of the hypothalamus-pituitary-adrenal axis. Psychosom Med 61:154-162. CrossRef Medline

Klorman R, Weissberg RP, Wiesenfeld AR (1977) Individual differences in fear and autonomic reactions to affective stimulation. Psychophysiology 14:45-51. CrossRef Medline

Klumpers F, Raemaekers MA, Ruigrok AN, Hermans EJ, Kenemans JL, Baas JM (2010) Prefrontal mechanisms of fear reduction after threat offset. Biol Psychiatry 68:1031-1038. CrossRef Medline

Klumpers F, Heitland I, Oosting RS, Kenemans JL, Baas JM (2012) Genetic variation in serotonin transporter function affects human fear expression indexed by fear-potentiated startle. Biol Psychol 89:277-282. CrossRef Medline

Klumpers F, Morgan B, Terburg D, Stein DJ, van Honk J (2015a) Impaired acquisition of classically conditioned fear-potentiated startle reflexes in humans with focal bilateral basolateral amygdala damage. Soc Cogn Affect Neurosci 10:1161-1168. CrossRef Medline

Klumpers F, Kroes MC, Heitland I, Everaerd D, Akkermans SE, Oosting RS, van Wingen G, Franke B, Kenemans JL, Fernández G, Baas JM (2015b) Dorsomedial prefrontal cortex mediates the impact of serotonin transporter linked polymorphic region genotype on anticipatory threat reactions. Biol Psychiatry 78:582-589. CrossRef Medline

Kriegeskorte N, Simmons WK, Bellgowan PS, Baker CI (2009) Circular analysis in systems neuroscience: the dangers of double dipping. Nat Neurosci 12:535-540. CrossRef Medline

Krüger O, Shiozawa T, Kreifelts B, Scheffler K, Ethofer T (2015) Three distinct fiber pathways of the bed nucleus of the stria terminalis to the amygdala and prefrontal cortex. Cortex 66:60-68. CrossRef Medline

Li J, Schiller D, Schoenbaum G, Phelps EA, Daw ND (2011) Differential roles of human striatum and amygdala in associative learning. Nat Neurosci 14:1250-1252. CrossRef Medline 
Lovick TA, Li P, Schenberg LC (1995) Modulation of the cardiovascular defence response by low frequency stimulation of a deep somatic nerve in rats. J Auton Nerv Syst 50:347-354. CrossRef Medline

Löw A, Lang PJ, Smith JC, Bradley MM (2008) Both predator and prey: emotional arousal in threat and reward. Psychol Sci 19:865-873. CrossRef Medline

Löw A, Weymar M, Hamm AO (2015) When threat is near, get out of here: dynamics of defensive behavior during freezing and active avoidance. Psychol Sci 26:1706-1716. CrossRef Medline

Maldjian JA, Laurienti PJ, Kraft RA, Burdette JH (2003) An automated method for neuroanatomic and cytoarchitectonic atlas-based interrogation of fMRI data sets. Neuroimage 19:1233-1239. CrossRef Medline

McCrory EJ, De Brito SA, Sebastian CL, Mechelli A, Bird G, Kelly PA, Viding E (2011) Heightened neural reactivity to threat in child victims of family violence. Curr Biol 21:R947-R948. CrossRef Medline

McDonald AJ (2003) Is there an amygdala and how far does it extend? An anatomical perspective. Ann N Y Acad Sci 985:1-21. CrossRef Medline

McMenamin BW, Langeslag SJ, Sirbu M, Padmala S, Pessoa L (2014) Network organization unfolds over time during periods of anxious anticipation. J Neurosci 34:11261-11273. CrossRef Medline

McNaughton N, Corr PJ (2004) A two-dimensional neuropsychology of defense: fear/anxiety and defensive distance. Neurosci Biobehav Rev 28: 285-305. CrossRef Medline

Mechias ML, Etkin A, Kalisch R (2010) A meta-analysis of instructed fear studies: implications for conscious appraisal of threat. Neuroimage 49: 1760-1768. CrossRef Medline

Meng XL, Rosenthal R, Rubin DB (1992) Comparing correlated correlation-coefficients. Psychol Bull 111:172-175. CrossRef

Miles L, Davis M, Walker D (2011) Phasic and sustained fear are pharmacologically dissociable in rats. Neuropsychopharmacology 36:1563-1574. CrossRef Medline

Mobbs D, Petrovic P, Marchant JL, Hassabis D, Weiskopf N, Seymour B, Dolan RJ, Frith CD (2007) When fear is near: threat imminence elicits prefrontal-periaqueductal gray shifts in humans. Science 317:1079-1083. CrossRef Medline

Mobbs D, Yu R, Rowe JB, Eich H, FeldmanHall O, Dalgleish T (2010) Neural activity associated with monitoring the oscillating threat value of a tarantula. Proc Natl Acad Sci U S A 107:20582-20586. CrossRef Medline

Mobbs D, Hagan CC, Dalgleish T, Silston B, Prévost C (2015) The ecology of human fear: survival optimization and the nervous system. Front Neurosci 9:55. Medline

Nalivaiko E, Salome N, Ngarampramuan S (2007) Amygdala blockade reduces tachycardia and modifies cardiac sympatho-vagal balance during restraint stress in rats. Auton Neurosci 135:38-39. CrossRef

Obrist PA, Webb RA, Sutterer JR, Howard JL (1970) The cardiac-somatic relationship: some reformulations. Psychophysiology 6:569-587. CrossRef Medline

Oler JA, Birn RM, Patriat R, Fox AS, Shelton SE, Burghy CA, Stodola DE, Essex MJ, Davidson RJ, Kalin NH (2012) Evidence for coordinated functional activity within the extended amygdala of non-human and human primates. Neuroimage 61:1059-1066. CrossRef Medline

Oler JA, Tromp DP, Fox AS, Kovner R, Davidson RJ, Alexander AL, McFarlin DR, Birn RM, Berg BE, deCampo DM, Kalin NH, Fudge JL (2017) Connectivity between the central nucleus of the amygdala and the bed nucleus of the stria terminalis in the non-human primate: neuronal tract tracing and developmental neuroimaging studies. Brain Struct Funct 222:21-39. CrossRef Medline

Oscar CG, Müller-Ribeiro FC, de Castro LG, Martins Lima A, CampagnoleSantos MJ, Santos RA, Xavier CH, Fontes MA (2015) Angiotensin-(1-7) in the basolateral amygdala attenuates the cardiovascular response evoked by acute emotional stress. Brain Res 1594:183-189. CrossRef Medline

Power JD, Barnes KA, Snyder AZ, Schlaggar BL, Petersen SE (2012) Spurious but systematic correlations in functional connectivity MRI networks arise from subject motion. Neuroimage 59:2142-2154. CrossRef Medline

Power JD, Mitra A, Laumann TO, Snyder AZ, Schlaggar BL, Petersen SE (2014) Methods to detect, characterize, and remove motion artifact in resting state fMRI. Neuroimage 84:320-341. CrossRef Medline
Price JL (2003) Comparative aspects of amygdala connectivity. Ann N Y Acad Sci 985:50-58. CrossRef Medline

Rau V, DeCola JP, Fanselow MS (2005) Stress-induced enhancement of fear learning: an animal model of posttraumatic stress disorder. Neurosci Biobehav Rev 29:1207-1223. CrossRef Medline

Satterthwaite TD, Wolf DH, Loughead J, Ruparel K, Elliott MA, Hakonarson H, Gur RC, Gur RE (2012) Impact of in-scanner head motion on multiple measures of functional connectivity: relevance for studies of neurodevelopment in youth. Neuroimage 60:623-632. CrossRef Medline

Scher CD, Stein MB, Asmundson GJ, McCreary DR, Forde DR (2001) The childhood trauma questionnaire in a community sample: psychometric properties and normative data. J Trauma Stress 14:843-857. CrossRef Medline

Shackman AJ, Fox AS (2016) Contributions of the central extended amygdala to fear and anxiety. J Neurosci 36:8050-8063. CrossRef Medline

Shackman AJ, Fox AS, Oler JA, Shelton SE, Oakes TR, Davidson RJ, Kalin NH (2017) Heightened extended amygdala metabolism following threat characterizes the early phenotypic risk to develop anxiety-related psychopathology. Mol Psychiatry 22:724-732. CrossRef Medline

Simmons JP, Nelson LD, Simonsohn U (2011) False-positive psychology: undisclosed flexibility in data collection and analysis allows presenting anything as significant. Psychol Sci 22:1359-1366. CrossRef Medline

Somerville LH, Whalen PJ, Kelley WM (2010) Human bed nucleus of the stria terminalis indexes hypervigilant threat monitoring. Biol Psychiatry 68:416-424. CrossRef Medline

Steiger JH (1980) Tests for comparing elements of a correlation matrix. Psychol Bull 87:245-251. CrossRef

Straube T, Mentzel HJ, Miltner WH (2007) Waiting for spiders: brain activation during anticipatory anxiety in spider phobics. Neuroimage 37: 1427-1436. CrossRef Medline

Teicher MH, Samson JA (2013) Childhood maltreatment and psychopathology: a case for ecophenotypic variants as clinically and neurobiologically distinct subtypes. Am J Psychiatry 170:1114-1133. CrossRef Medline

Thombs BD, Bernstein DP, Lobbestael J, Arntz A (2009) A validation study of the Dutch Childhood Trauma Questionnaire-Short Form: factor structure, reliability, and known-groups validity. Child Abuse Negl 33:518523. CrossRef Medline

Torrisi S, O'Connell K, Davis A, Reynolds R, Balderston N, Fudge JL, Grillon C, Ernst M (2015) Resting state connectivity of the bed nucleus of the stria terminalis at ultra-high field. Hum Brain Mapp 36:4076-4088. CrossRef Medline

Tovote P, Fadok JP, Lüthi A (2015) Neuronal circuits for fear and anxiety. Nat Rev Neurosci 16:317-331. CrossRef Medline

van Harmelen AL, van Tol MJ, Demenescu LR, van der Wee NJ, Veltman DJ, Aleman A, van Buchem MA, Spinhoven P, Penninx BW, Elzinga BM (2013) Enhanced amygdala reactivity to emotional faces in adults reporting childhood emotional maltreatment. Soc Cogn Affect Neurosci 8:362369. CrossRef Medline

van Marle HJ, Hermans EJ, Qin S, Fernández G (2010) Enhanced restingstate connectivity of amygdala in the immediate aftermath of acute psychological stress. Neuroimage 53:348-354. CrossRef Medline

Vul E, Harris C, Winkielman P, Pashler H (2009) Puzzlingly high correlations in fMRI studies of emotion, personality and social cognition. Perspect Psychol Sci 4:274-290. CrossRef Medline

Walker DL, Toufexis DJ, Davis M (2003) Role of the bed nucleus of the stria terminalis versus the amygdala in fear, stress, and anxiety. Eur J Pharmacol 463:199-216. CrossRef Medline

Wang X, Piñol RA, Byrne P, Mendelowitz D (2014) Optogenetic stimulation of locus ceruleus neurons augments inhibitory transmission to parasympathetic cardiac vagal neurons via activation of brainstem alphal and betal receptors. J Neurosci 34:6182-6189. CrossRef Medline

Woo CW, Krishnan A, Wager TD (2014) Cluster-extent based thresholding in fMRI analyses: pitfalls and recommendations. Neuroimage 91:412419. CrossRef Medline

Zald DH (2003) The human amygdala and the emotional evaluation of sensory stimuli. Brain Res Brain Res Rev 41:88-123. CrossRef Medline 